\title{
Increasing Incidence of Pediatric Eosinophilic Esophagitis in the Southwest of Madrid, Spain
}

\author{
La Orden Izquierdo E', Gutiérrez Junquera $C^{2}$, Mahillo-Fernández I³, Subiza Garrido-Lestache J4, \\ Román Riechmann $\mathrm{E}^{2}$
}

\begin{abstract}
${ }^{1}$ Hospital Universitario Infanta Elena, Valdemoro, Spain; Universidad Francisco de Vitoria, Pozuelo de Alarcón, Spain ${ }^{2}$ Hospital Universitario Puerta de Hierro Majadahonda, Majadahonda, Spain; Universidad Autónoma de Madrid, Madrid, Spain

${ }^{3}$ Hospital Universitario Fundación Jiménez Díaz, Madrid, Spain

${ }^{4}$ Clínica Subiza, Madrid, Spain
\end{abstract}

J Investig Allergol Clin Immunol 2019; Vol. 29(1): 24-29

doi: 10.18176/jiaci.0280

\begin{abstract}
Objectives: The incidence of eosinophilic esophagitis is unknown in our area. The aim of our study was to determine the incidence of eosinophilic esophagitis and its possible association with the most frequent absolute annual pollen counts.

Methods: A descriptive retrospective multicenter observational study was designed to calculate the incidence of eosinophilic esophagitis in children aged under 15 years in the southwest region of Madrid, Spain in 2002-2013 (data were provided by the Statistics Institute of Madrid). We collected data on age, sex, clinical presentation, and date of endoscopic diagnosis. Relative risk (RR) was estimated (Stata v.11) using negative binomial regression models to assess the association between incidence and pollen counts (provided by Subiza Clinic). Results: The study population comprised 254 patients (192 male [75.6\%], aged 0.5-14.99 years). The clinical presentation was esophageal impaction in $23.6 \%$, dysphagia in $22 \%$, gastroesophageal reflux-like symptoms in $44.9 \%$, and other findings in $9.4 \%$. The annual incidence from 2002 to 2013 per 100000 children aged <15 years per year was, respectively, 0.81, 1.5, 0.37, 3.17, 3.07, 4.36, 6.87, 7.19, 8.38, $9.05,9.14$, and 9.68. The incidence of eosinophilic esophagitis increased by an average of $19 \%$ annually $(\mathrm{RR}, 1.19 ; 95 \% \mathrm{Cl}, 1.14-1.25$; $P<.001)$. In the overall analysis, the relationship between incidence and absolute annual and monthly counts during the pollen seasons of the respective pollen types was analyzed only for Platanus species, which had an RR $>1$ (1.17 and 1.06, respectively) $(P<.05)$. Conclusion: The incidence of diagnosis of pediatric eosinophilic esophagitis increased by an average of $19 \%$ annually. No significant association was found between incidence and pollen counts, except for a weak association with Platanus species.
\end{abstract}

Key words: Pollen. Eosinophilic esophagitis. Epidemiology.

\section{Resumen}

Objetivo: La incidencia de esofagitis eosinofílica es desconocida en nuestra área. El objetivo de nuestro estudio es determinar la incidencia de diagnóstico de esofagitis eosinofílica y su posible asociación con los recuentos absolutos anuales de los pólenes más frecuentes. Métodos: Se diseñó un estudio descriptivo multicéntrico retrospectivo para el cálculo de la incidencia de esofagitis eosinofílica en niños menores de 15 años en el suroeste de la Comunidad de Madrid entre 2002-2013 (datos poblacionales obtenidos del Instituto de Estadística de la Comunidad de Madrid). Se recoge de cada paciente: edad, sexo, presentación clínica y fecha de diagnóstico endoscópico. Se estimó la asociación entre la incidencia y los recuentos polínicos (aportados por la Clínica Subiza) mediante cálculo del riesgo relativo usando modelos de regresión binomial negativa (Stata v.11).

Resultados: Se incluyeron 254 pacientes, 75,6\% varones ( $n=192)$, de edades comprendidas entre 0,5-14,99 años. La presentación clínica fue: impactación esofágica 23,6\%, disfagia 22\%, síntomas sugerentes de reflujo gastroesofágico $44,9 \%$ y otros $9,4 \%$. Las incidencias anuales desde 2002 a 2013 ( $n^{\circ}$ casos/100.000 niños menores de 15 años/año) fueron respectivamente: 0,81; 1,5; 0,37; 3,17; 3,07; 4,36; 6,$87 ; 7,19 ; 8,38 ; 9,05 ; 9,14$ y 9,68. La incidencia de esofagitis eosinofílica se incrementó en una media anual de 19\% (RR 1,19, 95\% IC: $1,14-1,25, p<0,001)$. En nuestro estudio únicamente existió asociación (RR>1) entre la incidencia y los recuentos polínicos absolutos de Platanus spp anuales y durante los meses de máxima polinización $(1,17$ and 1,06 , respectivamente) $(p<0,05)$.

Conclusión: La incidencia de diagnóstico de esofagitis eosinofílica en la edad pediátrica se ha incrementado en una media anual de un $19 \%$. No se encontró una asociación estadísticamente significativa entre la incidencia y los recuentos polínicos, excepto con el Platanus spp aunque ésta fue débil.

Palabras clave: Polen. Esofagitis eosinofílica. Epidemiología. 


\section{Introduction}

Eosinophilic esophagitis (EoE) is a chronic local immunemediated inflammatory process characterized clinically by symptoms suggestive of esophageal dysfunction and histologically by eosinophilic infiltration of the esophageal epithelium ( $>15$ eosinophils per high-power field). The definition of EoE excludes other causes of esophageal eosinophilia, whether local or systemic [1]. In young children, typical symptoms are similar to those of gastroesophageal reflux disease (GERD), and, in older children, dysphagia and food impaction [2]. Treatment includes dietary restriction for certain foods, exclusively proton pump inhibitor (PPI) treatment, topical corticosteroids, and other treatments $[3,4]$.

EoE is increasingly diagnosed in our setting [5]. In addition, the existence of a real increase in incidence, as reported in published epidemiological studies, is clear in other areas [6].

The incidence of EoE has been reported to be seasonal, although this has not been confirmed. Based on this factor and the pathogenic role attributed to food allergens, circulating aeroallergens may act as determinants of incidence and exacerbations through cross-reactivity $[7,8]$. However, this hypothesis remains controversial.

The objective of our study was to describe the incidence of EoE diagnosed in children under 15 years of age in the southwest of the region of Madrid, Spain between 2002 and 2013. The secondary objectives were to describe the clinical presentation pattern and to assess the relationship between the number of cases and the average level of circulating aeroallergens, both annually and in periods of peak pollen count.

\section{Patients and Methods}

We collected a retrospective sample of all patients under the age of 15 and newly diagnosed with EoE between 2002 and 2013 in 11 public hospitals in the southwest of the autonomous community of Madrid through review of electronic medical records. Cases were defined as patients with symptoms of esophageal dysfunction associated with the presence of esophageal eosinophilic infiltration $\geq 15$ eosinophils per highpower field [1], including patients who responded to PPIs. Patients with other causes of EoE were excluded, as were those not belonging to the referral area or diagnosed with EoE before 2002. The variables collected from each patient were sex, month of endoscopic diagnosis, age, and diagnostic symptoms (esophageal impaction, dysphagia, gastroesophageal refluxlike symptoms, and other). The study was approved by the local ethics committee.

In order to assess clinical manifestations related to age of presentation, the total sample was divided into 2 groups consisting of patients aged $<8$ years and patients aged $\geq 8$ years. In order to estimate the annual incidence, we used the referral population under 15 years of age for each hospital per year, as provided by the Statistics Institute of the region of Madrid (available at: http://www.madrid.org/iestadis/) (Table). This estimation was performed in the same way for each age group, taking the respective denominator in each case. The existence of statistically significant differences between the annual incidence by age group (patients $<8$ years and patients $\geq 8$ years) was analyzed using the Mantel-Haenszel test.

A negative binomial regression model was used to estimate the possible association (relative risk [RR]) between EoE diagnosed in the pediatric population and the pollen counts.

Table. Population Under 15 Years and Absolute Pollen Counts

\begin{tabular}{|c|c|c|c|c|c|c|c|c|c|c|c|c|}
\hline \multirow[b]{2}{*}{ Year } & \multirow[b]{2}{*}{$\begin{array}{l}\text { No. of } \\
\text { Cases }\end{array}$} & \multicolumn{3}{|c|}{ Population Under 15 Years of Age ${ }^{\mathrm{a}}$} & \multicolumn{8}{|c|}{ Absolute Pollen Counts, grains $/ \mathrm{m}^{3}$ of air ${ }^{\mathrm{b}}$} \\
\hline & & $\begin{array}{l}\text { Age } \\
<8 \text { y }\end{array}$ & $\begin{array}{l}\text { Age } \\
\geq 8 \mathrm{y}\end{array}$ & Total & $\mathrm{O}$ & $\mathrm{P}$ & Po & $\mathrm{C}$ & Q & A & $\mathrm{U}$ & AA \\
\hline 2002 & 1 & 132711 & 122541 & 255252 & 2605 & 7612 & 4985 & 9431 & 10886 & 72 & 619 & 3271 \\
\hline 2003 & 4 & 142088 & 123787 & 265875 & 2452 & 5850 & 3773 & 4096 & 6430 & 48 & 584 & 1617 \\
\hline 2004 & 1 & 150220 & 122957 & 273177 & 801 & 3405 & 2612 & 6027 & 3005 & 58 & 476 & 1130 \\
\hline 2005 & 9 & 160060 & 123857 & 283917 & 3581 & 8354 & 1889 & 2906 & 10956 & 47 & 322 & 1198 \\
\hline 2006 & 9 & 170119 & 123407 & 293526 & 2782 & 6471 & 5165 & 4456 & 5300 & 36 & 416 & 910 \\
\hline 2007 & 13 & 174431 & 123906 & 298337 & 2080 & 7738 & 6860 & 9499 & 7705 & 37 & 423 & 3087 \\
\hline 2008 & 21 & 178378 & 127238 & 305616 & 1211 & 10289 & 4425 & 7296 & 7682 & 51 & 519 & 3123 \\
\hline 2009 & 23 & 188256 & 131587 & 319843 & 3628 & 7409 & 2560 & 4709 & 8455 & 20 & 503 & 1497 \\
\hline 2010 & 39 & 272220 & 193351 & 465571 & 2071 & 11012 & 4176 & 4211 & 7399 & 50 & 385 & 2021 \\
\hline 2011 & 43 & 276494 & 198628 & 475122 & 3003 & 15871 & 4120 & 12875 & 10982 & 84 & 574 & 2909 \\
\hline 2012 & 44 & 277020 & 204568 & 481588 & 1876 & 13704 & 3487 & 4893 & 16155 & 22 & 428 & 697 \\
\hline 2013 & 47 & 274301 & 211054 & 485355 & 5502 & 7149 & 5698 & 7252 & 6201 & 69 & 561 & 929 \\
\hline
\end{tabular}

Abbreviations: O, Olea; P, Platanus; Po, Poaceae; C, Cupressaceae; Q, Quercus; A, Artemisia; U, Urticaceae; AA, Alternaria alternata. alnstitute of Statistics of the Madrid region.

bsubiza Clinic. 
The average annual absolute pollen counts of the main taxons in Madrid (Olea species, Platanus species, Poaceae, Artemisia species, Urticaceae, Cupressaceae, and Quercus species) were provided by the Subiza Clinic (available at: https://www.clinicasubiza.com). The analysis included counts of Alternaria alternata fungus, as this is the main allergic outdoor fungus and is present throughout the year (Table).

The diagnostic period was represented as an indicator variable in groups of 1 year. From these data, the RR of being diagnosed with EoE was estimated based on the pollen levels using negative binomial regression models [9].

The same calculation with the absolute maximum pollen counts in each pollination period (obtained from Public Health Technical Paper No. 70: "Atmospheric Pollen in Madrid", which is available for consultation at https://www.madrid.org/ polen), taking into account the incidence of cases in each period included. All calculations were performed using the statistical program Stata v.11. This study follows the principles for observational studies outlined in the Declaration of Helsinki.

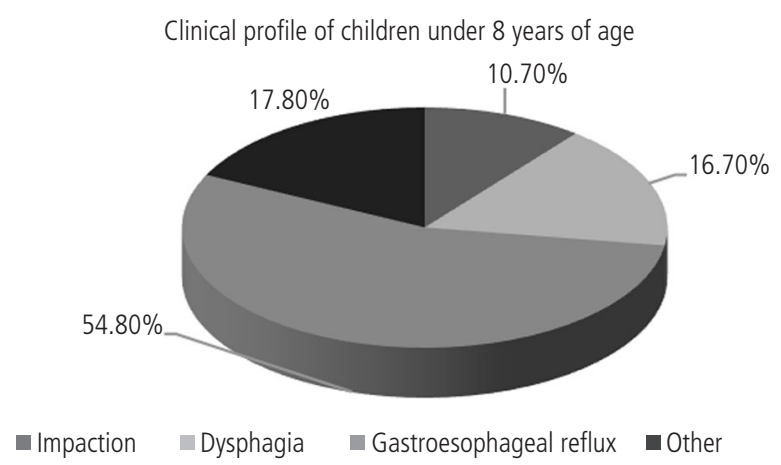

Clinical Profile of children equal to or older than 8 to 15 years of age

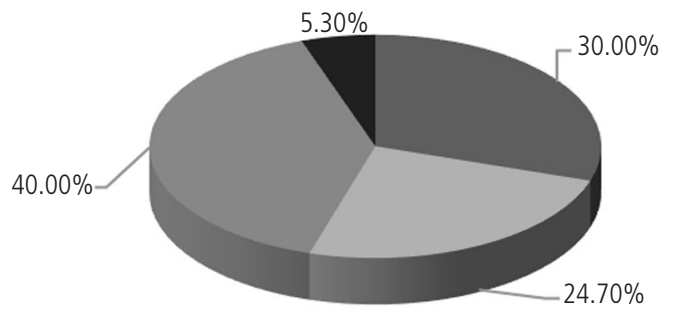

- Impaction $\square$ Dysphagia $\square$ Gastroesophageal reflux $\quad$ Other

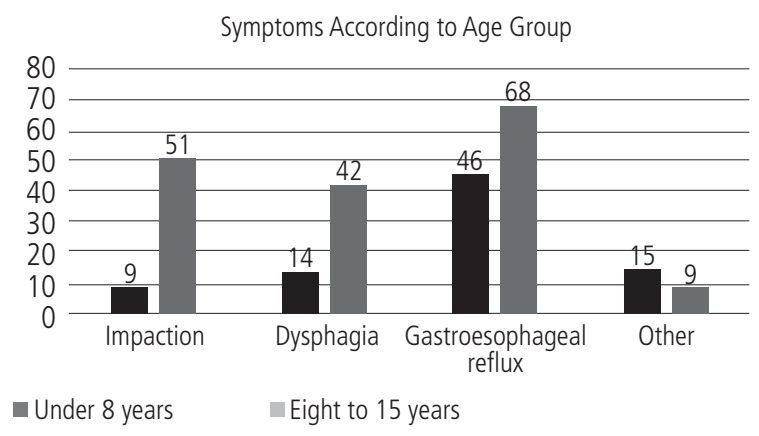

Figure 1. Clinical profile by age group.

\section{Results}

The study population comprised 254 patients (192 males [75.6\%]). Mean (SD) age was 9.24 (3.43) years (median [IQR], 9.67 [0.5-14.99]); mode, 6.6 years). Eighty-four patients were under 8 years, and 170 were 8 years to 15 years old. The clinical presentation was as follows: esophageal impaction, $23.6 \%(n=60)$; dysphagia, 22\% $(n=56)$; gastroesophageal reflux-like symptoms, $44.9 \%(\mathrm{n}=114)$; casual findings, $5.1 \%$ $(\mathrm{n}=13)$; and other findings (evaluated owing to low weight, diarrhea, Helicobacter pylori infection), $4.3 \%(n=11)$. Clinical presentation according to age group ( $<8$ years and $\geq 8$ years) is presented in Figure 1. Statistically significant differences were found between the groups $(P<.05)$.

The overall mean incidence of EoE was 6.04/100 000 children $<15$ years of age per year. Incidence was 3.50 in patients aged $<8$ years and 9.41 in those aged 8 years to 15 years. This difference was statistically significant (RR, 2.68; 95\%CI, 2.09-3.45; $P<.001)$.

The annual incidence from 2002 to 2013 was, respectively, $0.39,1.5,0.37,3.17,3.07,4.36,6.87,7.19,8.38,9.05,9.14$, and 9.68 cases/100 000 habitants aged $<15$ years/year. This upward trend is presented in overall terms and by age groups in Figure 2. It was estimated that, from 2002 to 2013, the incidence of EoE increased by an average of $19 \%$ annually (RR, 1.19; 95\%CI, 1.14-1.25; $P<.001$ ).

The overall analysis of the relationship between the incidence and the absolute pollen counts, both annually and monthly during the peak pollen count period (pollen season), only revealed a statistically significant association $(P<.05)$ with Platanus species, both annually and in the pollen season. However, the strength of this association was weak (RR, 1.06 and 1.10 , respectively). According to this model, a $6 \%$ and $10 \%$ increase in the risk of developing EoE is expected for every 1000-unit increase in Platanus pollen counts annually and monthly during the pollen season, respectively. There was no association with other pollen counts $(P>.05)$.

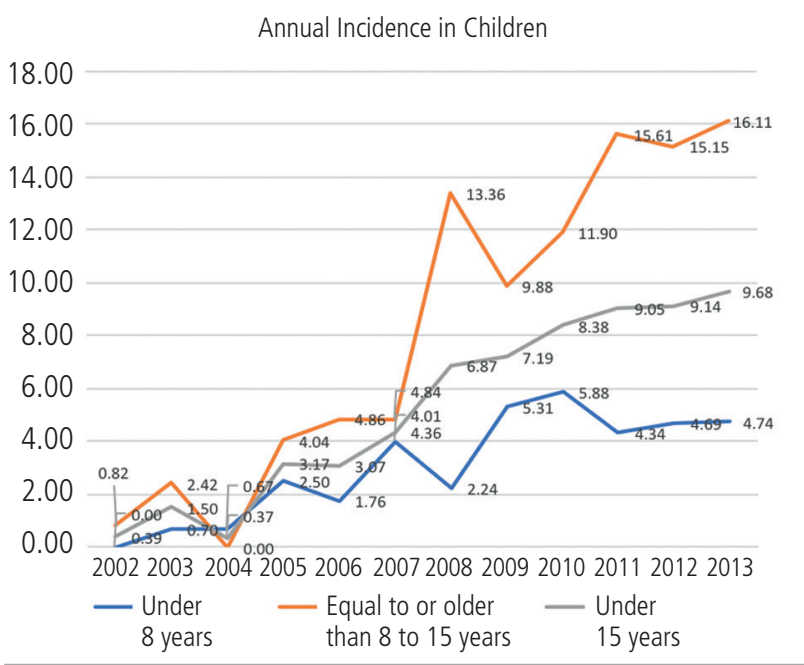

Figure 2. Annual incidence (number of cases/100 000 persons/year) both overall and by age group. 


\section{Discussion}

The incidence of pediatric EoE in our area has increased in recent years by an average of $19 \%$ annually and in 2013 stood at 9.7/100 000 children/year. These results corroborate published data, although the incidence varies widely according to the geographical area. The systematic review by Soon et al [10] published in 2013 found incidences ranging from 1.6/100 000 persons/year in Denmark to $10 / 100000$ persons/year in the USA, with an average annual increase of $12 \%-17 \%$ [10]. A recent systematic review of 2016 by Arias et al [6] supports these results, finding a global incidence in children of 5.1/100 000 persons/year (lower than in adults), with a significant increase in diagnosed disease in studies carried out from 2008. Geographical variations similar to those described by Soon et al were observed, with significant differences between the United States (5.4/100 000 persons/ year [95\%CI, 1.6-11.5]) and Europe (1.7/100 000 persons/ year $[95 \% \mathrm{CI}, 1.0-2.7]$ ) [6]. These values come mostly from retrospective studies.

Pediatric EoE series are scarce in Spain. A retrospective series from a hospital in Barcelona published in 2005 presented 11 newly diagnosed patients in the period running from January 1997 to November 2003, although no actual incidence data were reported [5]. Another series was from a prospective observational study that included 17 patients with a diagnosis of $\mathrm{EoE}$ ( $>20$ eosinophils per high-power field) in a hospital in Madrid from 2001 to 2009 [11]. Nevertheless, there are no reported data in Spain on incidence in children, and, to our knowledge, ours is the first study to provide data on the incidence of diagnosis of EoE in pediatric patients. We observed a clear increase in incidence during 2008-2009. This could be related to an increase in the number of endoscopies performed in the pediatric population, an active search for cases with greater diagnostic suspicion, and a real increase in the incidence of the disease.

In addition, some studies suggest that oral immunotherapy with food may also contribute to the increasing incidence of EoE, although we found no evidence for this possibility in our series [12].

Prospective series published in nearby regions include a mixed series of adults and children (age range, 6-63 years; mean age, 33.6 years) from 43 patients between 2006 and 2011 [13] and another pediatric series ( $<16$ years) of 35 patients from January 2011 to December 2015, with a mean age of 9.6 years (4-16 years) [14]. Given that the reference population is not included in any of them, it is impossible to calculate the incidence. On the other hand, our incidence data are similar to those of an adult population reported by Molina et al [15] in Spain during 2007-2016 that also included PPI responder cases [15].

The prevalence of males and mean age at diagnosis coincide with findings in other publications [10].

Clinical presentation is similar to that reported elsewhere [16] and, as described above, there is a variation in the clinical presentation according to age group [17], with more frequent occurrence as atypical gastroesophageal reflux-like symptoms that do not respond to usual treatment in patients aged $<8$ years and as dysphagia/impaction in patients aged
$>8$ years [10]. Statistically significant differences were found for annual incidence according to age group. The incidence in the younger group may actually be lower or underestimated because of unspecified symptoms. The time of onset of the histological abnormality is unknown, as is that of symptoms.

The relationship between EoE and aeroallergens is controversial. A recent systematic review found no significant variations in the seasonal distribution of the incidence of the disease [18]. However, seasonality and pollination are not a purely temporally static concept, but are conditioned by climatic changes (eg, rain patterns) or type of vegetation, which are variable. Thus, studies such as that of Moawad et al [7] and Fahey et al [8] show that there may be a correlation between the incidence of EoE and some aeroallergens, although to date it has been impossible to distinguish which ones may be responsible. A recent systematic review recognizes that seasonal, geographical, and climate-based differences in disease prevalence could be due to multiple environmental exposures, although the exact mediators of this process remain elusive [19].

In our study, we found no statistically significant association with any pollen type except for Platanus species, both annually and monthly during the peak period, although the strength of the association was weak. According to this model, we could assume that for every 1000-unit increase in this particle, a $10 \%$ increase in the risk of EoE is expected in persons aged $<15$ years. A study of the period 1979-1993 in Madrid found Platanus species to be the second most frequent pollen in this area [20]. The high degree of awareness of this pollen means that it is a major cause of hay fever in the Madrid area [21]. The theory of cross-reactivity between aeroallergens and food allergens [22,23] might explain its relationship with EoE. Thus, massive inhalation in high amounts would exceed mucociliary clearance and enable pollen to reach the esophagus. In a situation of increased mucosal permeability, the immunological relationship in deeper layers and the recruitment of eosinophils could be triggered [24]. The degree of contamination and suspended particles in inhaled air could act as a booster $[25,26]$.

The limitations of our study are partly a reflection of its retrospective nature. Incidence is probably underestimated because we excluded patients who were not included in the retrospective review and others from the catchment area who were diagnosed in other private or public centers. Therefore, our data reflect a minimal incidence of diagnosis. On the other hand, since we have no data about sensitization to Platanus species and other aeroallergens in these patients, we cannot establish a possible relationship. We did not evaluate the modifying effect of other environmental factors (eg, pollutants) on this association.

Given the retrospective nature of our study, the time of onset of symptoms was not accurately recorded. Onset of symptoms might more accurately express the onset of the disease, thus reducing the time to diagnosis. However, it is known that the disease can be detected as an incidental finding in endoscopies performed for other reasons, that the symptoms may be intermittent, and that inflammation may precede symptoms at onset [27]. Therefore, it is not possible to analyze whether the onset of symptoms is influenced or not by pollen counts. 
Pollen counts were monitored in the center of Madrid. Although the origin of the data of absolute pollen counts reflects the variations of absolute pollen counts during each year, the pollen count could be different at various points in the same area, as it depends on the local vegetation.

In conclusion, our study is the first of its kind to provide data on the incidence of EoE in a pediatric population residing in an area of Madrid and demonstrates the real increase in this diagnosis over a 12-year period. We observed a weak association between the incidence and annual pollen counts of Platanus species. Well-designed prospective studies are needed to confirm these findings and should account for other factors such as environmental contamination.

\section{Acknowledgments}

We are grateful to the following professionals, who provided care for study patients and collected data.

- Cilleruelo Pascual ML, Hospital Universitario Puerta de Hierro, Majadahonda.

- Fernández Fernández S, Hospital Universitario Severo Ochoa, Leganés.

- Rayo Fernández AI, Hospital Universitario Severo Ochoa, Leganés.

- Barrio Torres J, Hospital Universitario. de Fuenlabrada, Fuenlabrada.

- Botija Arcos G, Hospital Universitario Fundación Hospital de Alcorcón, Alcorcón.

- Barrio Merino A, Hospital Universitario Fundación Hospital de Alcorcón, Alcorcón.

- Urruzuno Tellería P, Hospital Universitario Doce de Octubre, Madrid.

- Medina Benítez E, Hospital Universitario Doce de Octubre, Madrid.

- Salcedo Lobato E, Hospital Universitario Doce de Octubre, Madrid.

- Grande Herrero L, Hospital Universitario de Getafe, Getafe.

- Miranda Cid C, Hospital Universitario Infanta Cristina, Parla.

- Rodrigo García G, Hospital Universitario Infanta Cristina, Parla.

- Herrero Álvarez M, Hospital Universitario Rey Juan Carlos, Móstoles.

- Carabaño Aguado I, Hospital Universitario Rey Juan Carlos, Móstoles.

- Sebastián Planas M, Hospital Universitario De Móstoles, Móstoles.

- Lancho Monreal E, Hospital Universitario de Aranjuez, Aranjuez.

- Romero Hombrebueno N, Hospital Universitario de Aranjuez, Aranjuez.

\section{Funding}

The authors confirm that no funding was received for the present study.

\section{Conflicts of Interest}

The authors declare that they have no conflicts of interest.

\section{References}

1. Lucendo AJ, Molina-Infante J, Arias Á, von Arnim U, Bredenoord AJ, Bussmann C, et al. Guidelines on eosinophilic esophagitis: evidence-based statements and recommendations for diagnosis and management in children and adults. United Eur Gastroenterol J. 2017;5:335-58.

2. Liacouras CA, Spergel JM, Ruchelli E, Verma R, Mascarenhas $M$, Semeao E, et al. Eosinophilic esophagitis: a 10-year experience in 381 children. Clin Gastroenterol Hepatol Off Clin Pract J Am Gastroenterol Assoc. 2005;3:1198-206.

3. Martín de Carpi J, Gómez Chiari $M$, Castejón Ponce $E$, Masiques Mas ML, Vilar Escrigas P, Varea Calderón V. [Increasing diagnosis of Eosinophilic esophagitis in Spain]. An Pediatría Barc Spain. 2005;62:333-9.

4. Richter JE. Current Management of Eosinophilic Esophagitis 2015. J Clin Gastroenterol. 2016;50:99-110.

5. Papadopoulou A, Koletzko S, Heuschkel R, Dias JA, Allen $\mathrm{KJ}$, Murch SH, et al. Management guidelines of eosinophilic esophagitis in childhood. J Pediatr Gastroenterol Nutr. 2014;58:107-18.

6. Arias Á, Pérez-Martínez I, Tenías JM, Lucendo AJ. Systematic review with meta-analysis: the incidence and prevalence of eosinophilic oesophagitis in children and adults in populationbased studies. Aliment Pharmacol Ther. 2016;43:3-15.

7. Moawad FJ, Veerappan GR, Lake JM, Maydonovitch CL, Haymore BR, Kosisky SE, et al. Correlation between eosinophilic oesophagitis and aeroallergens. Aliment Pharmacol Ther. 2010;31:509-15.

8. Fahey L, Robinson G, Weinberger K, Giambrone AE, Solomon AB. Correlation between Aeroallergen Levels and New Diagnosis of Eosinophilic Esophagitis in NYC. J Pediatr Gastroenterol Nutr. 2017;64:22-5.

9. Díaz-Quijano FA. Regresiones aplicadas al estudio de eventos discretos en epidemiología. Rev Univ Ind Santander Salud. 2016;48:9-15.

10. Soon IS, Butzner JD, Kaplan GG, deBruyn JCC. Incidence and prevalence of eosinophilic esophagitis in children. J Pediatr Gastroenterol Nutr. 2013;57:72-80.

11. Rizo Pascual JM, De la Hoz Caballer B, Redondo Verge C, Terrados Cepeda S, Roy Ariño G, Riesco López JM, Camarero Salces C. Allergy assessment in children with eosinophilic esophagitis. J Investig Allergol Clin Immunol. 2011;21:59-65.

12. Echeverría-Zudaire LA, Férnandez-Fernández $S$, RayoFernández A, Muñoz-Archidona C, Checa-Rodríguez R. Primary eosinophilic gastrointestinal disorders in children who have received food oral immunotherapy. Allergol Immunopathol (Madr). 2016;44(6):531-6.

13. Castro Jiménez A, Gómez Torrijos E, García Rodríguez R, Feo Brito F, Borja Segade J, Galindo Bonilla PA, et al. Demographic, clinical and allergological characteristics of Eosinophilic Esophagitis in a Spanish central region. Allergollmmunopathol (Madr). 2014;42:407-14.

14. Gómez Torrijos E, Sánchez Miranda P, Donado Palencia P, Castro Jimenez A, Rodriguez Sánchez J, Mendez Díaz Y, et al. Eosinophilic esophagitis: Demographic, clinical, endoscopic, histological and allergological characteristics in children and teenagers in a region of central Spain. J Investig Allergol Clin Immunol. 2017;27:104-10. 
15. Molina-Infante J, González-Cordero PL, Ferreira-Nossa HC, Mata-Romero P, Lucendo AJ, Arias A. Rising incidence and prevalence of adult eosinophilic esophagitis in midwestern Spain (2007-2016). United European Gastroenterology Journal. 2017;0:1-9.

16. Bystrom J, O'Shea NR. Eosinophilic oesophagitis: clinical presentation and pathogenesis. Postgrad Med. J 2014;90:282-9.

17. Noel RJ, Putnam PE, Rothenberg ME. Eosinophilic esophagitis. N Engl J Med. 2004;26;351:940-1.

18. Lucendo AJ, Arias Á, Redondo-González O, González-Cervera J. Seasonal distribution of initial diagnosis and clinical recrudescence of eosinophilic esophagitis: a systematic review and meta-analysis. Allergy. 2015;70:1640-50.

19. Green DJ, Cotton CC, Dellon ES. The Role of Environmental Exposures in the Etiology of Eosinophilic Esophagitis: A Systematic Review. Mayo Clin Proc. 2015;90:1400-10.

20. Subiza J, Jerez $M$, Jiménez JA, Narganes MJ, Cabrera M, Varela $S$, et al. Allergenic pollen and pollinosis in Madrid. J Allergy Clin Immunol. 1995;96:15-23.

21. Varela S, Subiza J, Subiza JL, Rodríguez R, García B, Jerez M, et al. Platanus pollen as an important cause of pollinosis. J Allergy Clin Immunol. 1997; 100:748-54.

22. Werfel T, Asero R, Ballmer-Weber BK, Beyer K, Enrique E, Knulst $A C$, et al. Position paper of the EAACl: food allergy due to immunological cross-reactions with common inhalant allergens. Allergy. 2015;70:1079-90.

23. Bartra J, Sastre J, del Cuvillo A, Montoro J, Jáuregui I, Dávila I, et al. From pollinosis to digestive allergy. J Investig Allergol Clin Immunol. 2009;19(Suppl 1):3-10.
24. Furuta GT, Katzka DA. Eosinophilic Esophagitis. N Engl J Med. 2015;22;373:1640-8.

25. Sedghy F, Sankian M, Moghadam M, Ghasemi Z, Mahmoudi $M$, Varasteh A-R. Impact of traffic-related air pollution on the expression of Platanus orientalis pollen allergens. Int J Biometeorol. 2017;61:1-9.

26. Sénéchal H, Visez N, Charpin D, Shahali Y, Peltre G, Biolley J-P, et al. A Review of the Effects of Major Atmospheric Pollutants on Pollen Grains, Pollen Content, and Allergenicity. Scientific World Journal. 2015;2015:940243.

27. Pentiuk S, Putnam PE, Collins MH, Rothenberg ME. Dissociation between symptoms and histological severity in pediatric eosinophilic esophagitis. J Pediatr Gastroenterol Nutr. 2009;48:152-60.

Manuscript received February 2, 2018; accepted for publication May 28, 2018.

\section{- Enrique La Orden Izquierdo}

Hospital Universitario Infanta Elena

E-mail: enrique.orden@quironsalud.es 